\title{
Lead recovery and the feasibility of foam glass production from funnel glass of dismantled cathode ray tube through pyrovacuum process
}

\author{
Mengjun Chen, Fu-Shen Zhang*, Jianxin Zhu \\ Research Center for Eco-Environmental Sciences, Chinese Academy of Sciences, 18 Shuangqing Road, Beijing 100085, China
}

\section{A R T I C L E I N F O}

\section{Article history:}

Received 24 January 2008

Received in revised form 18 April 2008

Accepted 18 April 2008

Available online 29 April 2008

\section{Keywords:}

Pyrovacuum reduction

CRT

Hazardous waste

Heavy metal

Leaching

\begin{abstract}
A B S T R A C T
Cathode ray tube (CRT) is the first and foremost problem that must be solved in electronic waste disposal, and the key of which lies in the detoxification and reutilization of lead-contained funnel glass. In this study, a novel and effective process for funnel glass of dismantled CRT treatment was developed. The key point of the process was to recover metallic lead from the funnel glass and to prepare foam glass synchronously. Experimental results showed that lead recovery rate increased first with the increase of temperature, carbon adding amount, and holding time, then reached a plateau value, but pressure was on the contrary. The optimum temperature, pressure, carbon adding amount and holding time for lead recovery were $1000^{\circ} \mathrm{C}, 1000 \mathrm{~Pa}, 5 \%$ and $4 \mathrm{~h}$, respectively, and the maximum lead recovery rate was $98.6 \%$. In the pyrovacuum process, lead in the funnel glass was firstly detached and changed to $\mathrm{PbO}$, then reduced and evaporated, and was recovered in the form of pure metal with a purity of $99.3 \%$. The residue porous glass was environmentally acceptable for construction application.
\end{abstract}

(c) 2008 Elsevier B.V. All rights reserved.

\section{Introduction}

The use of electrical and electronic equipment (EEE) has dramatically proliferated in recent decades, and proportionately, the quantity of wastes from EEE (WEEE), such as personal computers (PC), mobile telephones and entertainment electronics, is growing rapidly. It has been reported that the growth trend of WEEE represents a growth three times faster than that of the average municipal waste [1].

With regard to China, WEEE is generally sourced both from domestic generation and illegal imports. For domestic generation, TVs, refrigerators, washing machines and PCs are the main items. These equipments were widely used in the middle or the latter of the 1980s, and should have been replaced by new types after 2000 . For example, there are more than 5 million TV sets, 4 million refrigerators, 6 million washing machines, 5 million personal computers and 10 million units of mobile telephones were discarded after 2001 [2]. On the other hand, China is the destination for a substantial proportion of WEEE from developed countries, e.g., representatives within the United States' recycling industry have indicated that around $80 \%$ of the WEEE they receive is exported to Asia, and $90 \%$ of which goes to China [3]. Accordingly, WEEE is becoming a significant waste stream, both in terms of quantity and toxicity,

\footnotetext{
* Corresponding author. Tel.: +86 10 62849515; fax: +861062849515.

E-mail address: fszhang@rcees.ac.cn (F.-S. Zhang).
}

causing a severe problem to the environment, people health and sustainable economic growth. Guiyu, located in southern China, is one of the most representative examples, where thousands of farmers, without protective equipments, are now engaged in primitive and highly polluting electronic waste recycling [4].

At present, the WEEE recycling industry is typically disorganized in China, and the situation of which has been well summarized by He et al. [5] and Liu et al. [6]. Valuable matters in WEEE, such as copper loop, electronic gun, printed circuit board etc., are generally separated and collected for monetary purpose, but the hazardous and less valuable materials are usually discarded. Thus the key point to serve this situation is to recycle and disposal such types of wastes. Among these materials, cathode ray tube (CRT) glass should be considered firstly. Waste CRT, containing high content of $\mathrm{Pb}$ in the funnel glass (20-30\% $\mathrm{PbO}$ [7]), has been listed by the China EPA as hazardous waste. It has been reported that this type of waste accounts for approximately $47 \%$ by weight of commercial electronic devices and $30 \%$ by weight of data processing equipment [8].

In recent years, many scholars have paid great attention to the recycling of CRT glasses, and both closed-loop recycling (waste CRT to new CRT) and open-loop recycling (waste CRT to new products such as foam glass) were promoted. For the manufacture of new CRT, it could be profitable only in the case of an absolute separation of the lead-contained and uncontained glass, because the introduction of lead-contained glass in panel manufacturing is not acceptable for the solarization effect [1]. On the other hand, the 
Table 1

Chemical composition of the investigated funnel glass by X-ray fluorescence (XRF)

\begin{tabular}{lr}
\hline Oxide & wt\% \\
\hline $\mathrm{SiO}_{2}$ & 49.61 \\
$\mathrm{PbO}$ & 24.17 \\
$\mathrm{~K}_{2} \mathrm{O}$ & 7.79 \\
$\mathrm{Na}_{2} \mathrm{O}$ & 5.32 \\
$\mathrm{Al}_{2} \mathrm{O}_{3}$ & 3.63 \\
$\mathrm{SrO}$ & 2.99 \\
$\mathrm{CaO}$ & 2.30 \\
$\mathrm{BaO}$ & 1.96 \\
$\mathrm{MgO}$ & 1.49 \\
$\mathrm{ZrO}_{2}$ & 0.58 \\
$\mathrm{Fe}_{2} \mathrm{O}_{3}$ & 0.07 \\
$\mathrm{P}_{2} \mathrm{O}_{5}$ & 0.07 \\
\hline
\end{tabular}

addition of panel glass to the funnel or neck glass is limited, since the mixture of $\mathrm{Pb}$ and Ba glasses has inferior mechanical properties [9]. Moreover, new products such as Liquid Crystal Display (LCD) and Plasma Display Panel (PDP) significantly cut down the production scale of CRT TVs in the very near future. Therefore, a dramatic reduction of closed-loop recycling is anticipated. Accordingly, most of recent studies on waste CRT mainly focused on open-loop recycling, e.g., it has been used as second raw material to manufacture lead glass [10], glass foam [11,12], glass matrix composites [13,14], glass-ceramics [15,16], and glaze [17].

Although funnel glass recycling is the key point of CRT glass recycling, only limited previous reports discussed funnel glass reutilization [18,19]. Among these reports, dangerous heavy metal lead was generally transferred from the hazardous waste to new products but not removed or separated, hence the threat still remains. On some occasions, for example, glass foam prepared by powder technology from wasted CRT funnel glass [19], the threat could even be more aggregated because lead and other metals changed to crystal state from vitreous state which increased their leaching ability doubtlessly. As to our best knowledge, no other studies were reported on how to effectively separate lead from funnel glass except a report by ICER (2003) who concluded that this might be the last choice [20].

The objectives of this research were to: (1) examine lead recovery efficiency from funnel glass by pyrovacuum reduction and optimize the affecting factors; (2) synchronously transfer the residue into foam glass in the reduction process and evaluate the environmental safety of the product.

\section{Materials and methods}

\subsection{Sample preparation}

Funnel glasses of PC monitor was provided by Huaxing Environmental Protection Corporation. The glass was crushed into small pieces (around $3 \mathrm{~cm}$ ) and coatings were fully removed by wetscrubbing method [21]. Then the cleaned funnel glass particles were dry ball milled and sieved to smaller than 80 mesh, and the powder obtained was dried at $105^{\circ} \mathrm{C}$ for $24 \mathrm{~h}$. Chemical composition of the glass powder was examined by XRF and the results were presented in Table 1. Other materials used in the experiments were all analytical reagents unless otherwise mentioned.

\subsection{Pyrovacuum reduction process}

A brief scheme of the experimental system was shown in Fig. 1. In the pyrovacuum process, $5.00 \mathrm{~g}$ funnel glass powder were homogeneously mixed with $0-9 \%$ carbon powder (particle size $<100$ mesh, employed as reducing agent), and loaded in the sample boat, which was then placed in a quartz tube. The quartz tube was previ-

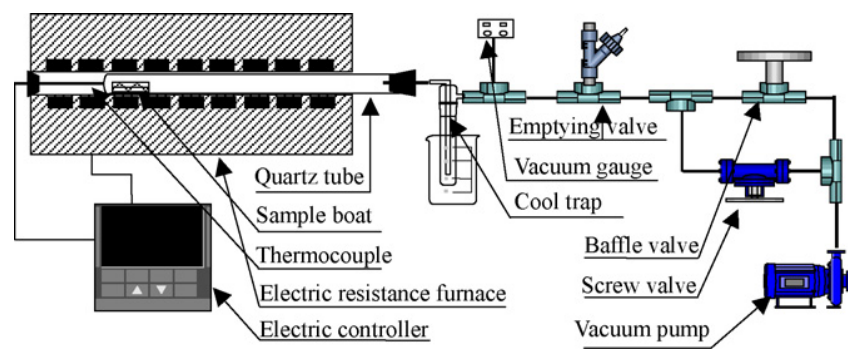

Fig. 1. Schematic diagram of the experimental system.

ously pumped to the setting pressure, then directly inserted to the tubular furnace (heated to the preset temperature) and held for $0.5-6 \mathrm{~h}$. After pyrovacuum treatment, the quartz tube was taken out and cooled down to room temperature. Then the quartz tube was released to the ambient pressure, and the residue in the boat was taken out and weighed. The examined temperatures were 600 , $700,800,900$ and $1000^{\circ} \mathrm{C}$, vacuum pressures were $10,100,1000$ and $10,000 \mathrm{~Pa}$, carbon adding amounts were $0,2,5$ and $9 \%$, and holding times were $0.5,1,2,4$ and $6 \mathrm{~h}$, respectively.

\subsection{Residue analysis}

After the treatment, the residues were digested $\left(\mathrm{HNO}_{3}-\mathrm{HClO}_{4}-\mathrm{HF}\right)$ [22] and analyzed by Inductively Coupled Plasma Optical Emission Spectrometer (ICP-OES, OPTIMA 2000, PerkinElmer, USA). Lead recovery rates were calculated according to the lead content before and after the pyrovacuum reduction treatment.

The recovered metal were characterized by X-ray diffraction (XRD) using the Ni-filtered $\mathrm{Cu} K \alpha$ radiation on a Rigaku D/MAX2500 diffractometer. Lead leaching behavior of the residues was evaluated according to the Toxicity Characteristic Leaching Procedure (TCLP) of USEPA. The morphology of the foam residue was examined by scanning electron microscopy (SEM, S-3000N, Hitachi, Japan).

\section{Results and discussion}

\subsection{Effect of temperature on lead recovery rate}

In the pyrovacuum process, lead oxide in the funnel glass is considered to be firstly reduced to metallic lead, then the lead evaporated into gaseous phase and was recovered after cooled down. Temperature is a key factor for both lead oxide reduction and metallic lead evaporation. Fig. 2 shows that lead recovery rate increased sharply with the increase of temperature below $800^{\circ} \mathrm{C}$, e.g., increased from $21.9 \%$ at $600{ }^{\circ} \mathrm{C}$ to $89.1 \%$ at $800{ }^{\circ} \mathrm{C}$, then reached a plateau value at above $800^{\circ} \mathrm{C}$. When the temperature is $1000^{\circ} \mathrm{C}$, lead recovery rate reached $97.5 \%$.

The stoichiometry of lead monoxide reduction by carbon powder in the funnel glass could be illustrated as follows [23,24]:

$\mathrm{PbO}_{(\mathrm{s})}+\mathrm{C}_{(\mathrm{s})}=\mathrm{CO}_{(\mathrm{g})}+\mathrm{Pb}_{(\mathrm{g})}$

$\Delta G_{T}=289427-481.88 T+2 R T \ln p\left(328-885^{\circ} \mathrm{C}\right)$

where $\Delta G_{T}$ is the Gibbs free energy at a certain temperature, $R$ is the universal gas constant, $T$ is treatment temperature and $p$ is the system pressure. The redox reaction between $\mathrm{PbO}$ and $\mathrm{C}$ takes place when $\Delta G_{T}<0$. Under the pyrovacuum conditions in this study ( $p=10 \mathrm{~Pa}$ ), according to Eq. (2), PbO can be reduced to $\mathrm{Pb}$ by carbon when the temperature is higher than $380^{\circ} \mathrm{C}\left(\Delta G_{T}=0\right.$, $\left.T=380^{\circ} \mathrm{C}\right)$. Since the examined temperatures in the experiments 


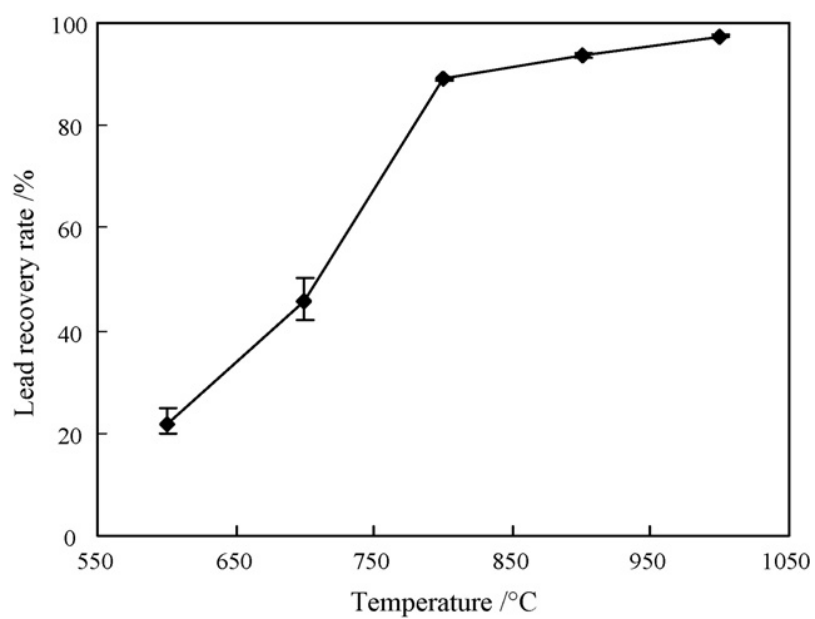

Fig. 2. Effect of temperature on lead recovery rate. Other conditions: pressure $=10 \mathrm{~Pa}$; carbon adding amount $=9 \%$; holding time $=4 \mathrm{~h}$.

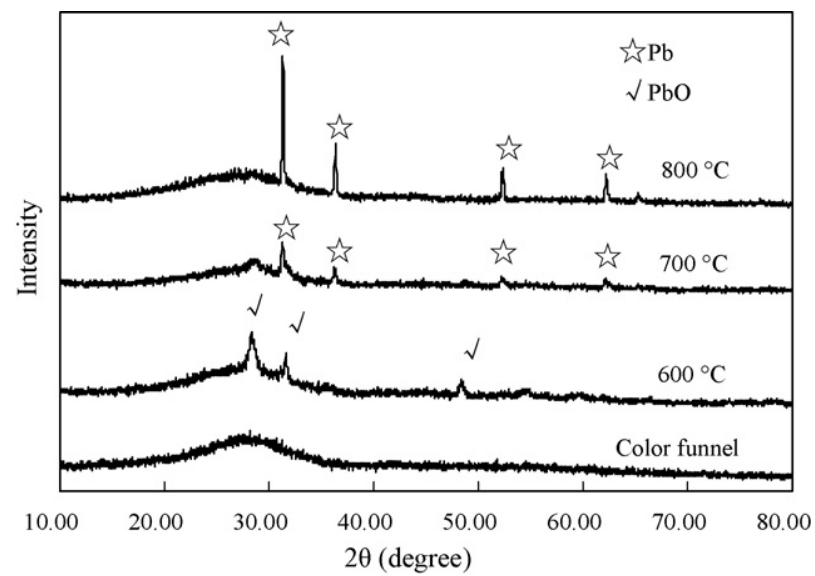

Fig. 3. XRD patterns of raw funnel glass powder and pyrovacuum residues. Other conditions for the residues: pressure $=10 \mathrm{~Pa}$, carbon adding amount $=9 \%$, holding time $=4 \mathrm{~h}$.

were all higher than $380^{\circ} \mathrm{C}$, PbO in the glass sample was considered to be reduced to metallic $\mathrm{Pb}$, but lower recovery rate for $\mathrm{Pb}$ was obtained within $380-800^{\circ} \mathrm{C}$, indicating that the reduced $\mathrm{Pb}$ could not be effectively recovered. Therefore, the key factor restricting $\mathrm{Pb}$ recovery rate at $<800^{\circ} \mathrm{C}$ was the evaporating velocity of the reduced $\mathrm{Pb}$. This could be attributed to the fact that the saturated

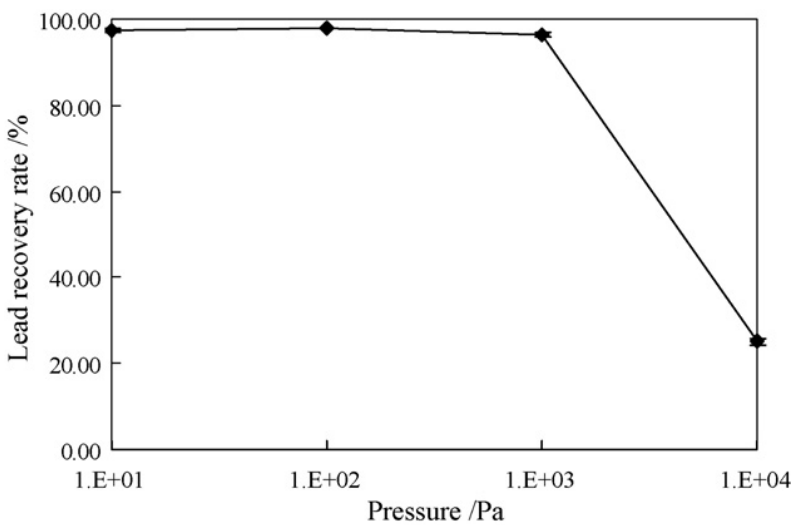

Fig. 4. Effect of pressure on lead recovery rate. Other conditions: temperature $=1000{ }^{\circ} \mathrm{C}$, carbon adding amount $=9 \%$, holding time $=4 \mathrm{~h}$.

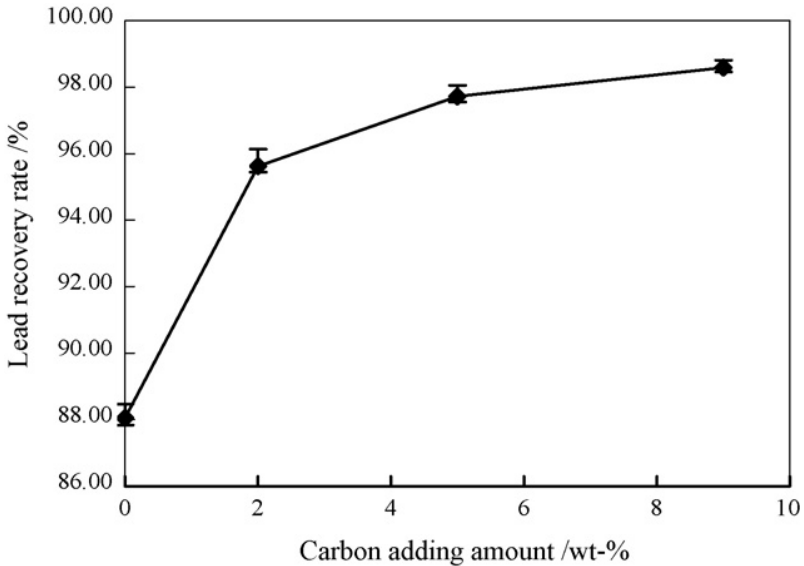

Fig. 5. Effect of carbon adding amount on lead recovery rate. Other conditions: temperature $=1000^{\circ} \mathrm{C}$, pressure $=1000 \mathrm{~Pa}$, holding time $=4 \mathrm{~h}$

vapor pressure of metallic lead was significantly lower than the operation pressure $10 \mathrm{~Pa}$, e.g., at $700^{\circ} \mathrm{C}$, the saturated vapor pressure of metallic lead is merely about $0.1 \mathrm{~Pa}$. At above $800^{\circ} \mathrm{C}$, the reduced metallic $\mathrm{Pb}$ could immediately evaporate and be recovered since the boiling point of $\mathrm{Pb}$ was about $800^{\circ} \mathrm{C}$ at $10 \mathrm{~Pa}[24]$, thus a plateau value was reached.

Fig. 3 presents the XRD patterns of the original funnel glass and the pyrovacuum residues obtained at different temperatures. No crystalline phase for the original glass sample was observed, but crystalline $\mathrm{PbO}$ appeared at $600^{\circ} \mathrm{C}$ and the diffraction peaks of metallic $\mathrm{Pb}$ appeared while $\mathrm{PbO}$ disappeared at $700^{\circ} \mathrm{C}$ or higher. It is well known that funnel glass is mainly produced from $\mathrm{Pb}_{3} \mathrm{O}_{4}$ (instead of $\mathrm{PbO}$ ) to ensure oxidizing conditions, therefore a certain amount of oxygen is dissolved within the funnel glass. Accordingly, a possible mechanism for $\mathrm{Pb}$ recovery in the pyrovacuum process was proposed: at around $600^{\circ} \mathrm{C}$, the dissolved oxygen was attacked by carbon and released, the local structure of the lead oxide in the funnel glass changed leading it detaching from the funnel glass, thus crystalline $\mathrm{PbO}$ was formed. Along with the further increase of the temperature, $\mathrm{PbO}$ was completely reduced by carbon to $\mathrm{Pb}$, and then $\mathrm{Pb}$ evaporated and was recovered.

\subsection{Effect of pressure on lead recovery rate}

Lead removal rate was almost the same (nearly 100\%) when the pressure was lower than $1000 \mathrm{~Pa}$, but it dropped down extremely at pressure higher than $1000 \mathrm{~Pa}$, e.g., about $20 \%$ at $10,000 \mathrm{~Pa}$ (Fig. 4). Therefore, $1000 \mathrm{~Pa}$ is considered to be the optimum pressure.

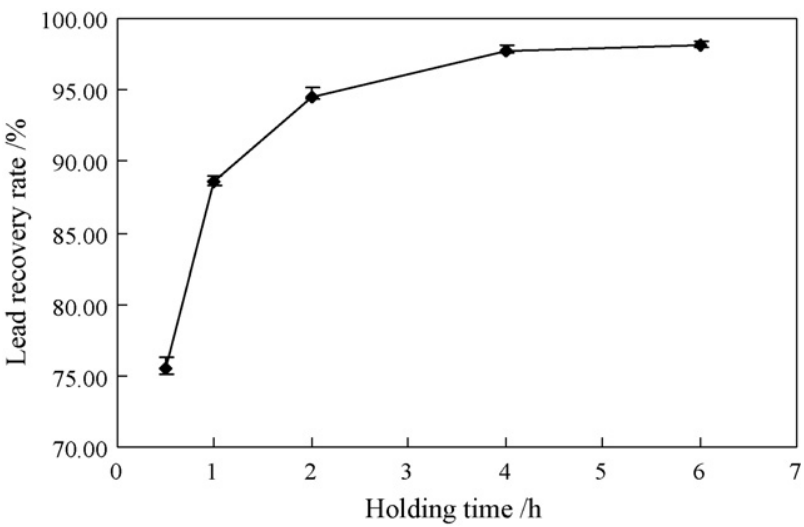

Fig. 6. Effect of holding time on lead recovery rate. Other conditions: temperature $=1000^{\circ} \mathrm{C}$, pressure $=1000 \mathrm{~Pa}$, carbon adding amount $=5 \%$. 


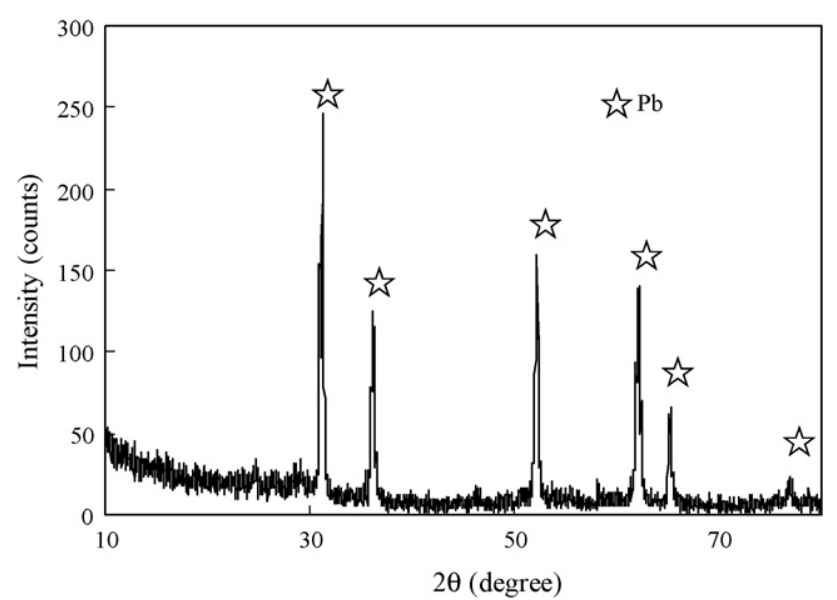

Fig. 7. XRD pattern of recovered metal.

System pressure, which affects lead evaporation velocity greatly, is another key point to the lead recovery rate. Generally, at a constant temperature and pressure ( $<1000 \mathrm{~Pa})$, metal evaporation velocity increases sharply with the decrease of pressure, and then reaches its maximum as the pressure reducing to a certain value. This pressure is called critical pressure. According to a previous report [24], the critical pressure of lead at $1000^{\circ} \mathrm{C}$ is $100 \mathrm{~Pa}$, therefore $100 \mathrm{~Pa}$ is considered to be the turning point of Fig. 4, but the turning point found in Fig. 4 is $1000 \mathrm{~Pa}$, where lead recovery rate is thought to be much lower than those of $100 \mathrm{~Pa}$ and $10 \mathrm{~Pa}$. This indicates that lead evaporation velocity of $1000 \mathrm{~Pa}$ is still faster enough for lead completely evaporating from the funnel glass within $4 \mathrm{~h}$, although it is far lower than those of $100 \mathrm{~Pa}$ and $10 \mathrm{~Pa}$.

\subsection{Effect of carbon and holding time on lead recovery rate}

Fig. 5 indicates the effect of carbon adding amount on the lead recovery rate. Lead recovery rate increased with the increase of carbon adding amount, and then reached its maximum value at $5 \%$. This percentage was considered to be the optimum carbon adding amount.

Fig. 6 illustrates that the highest lead recovery rate was obtained at a holding time of $4 \mathrm{~h}$. Therefore, it is recommended that $4 \mathrm{~h}$ is the optimum holding time with temperature, pressure and carbon adding amount fixed at $1000^{\circ} \mathrm{C}, 10 \mathrm{~Pa}$ and $5 \%$, respectively.

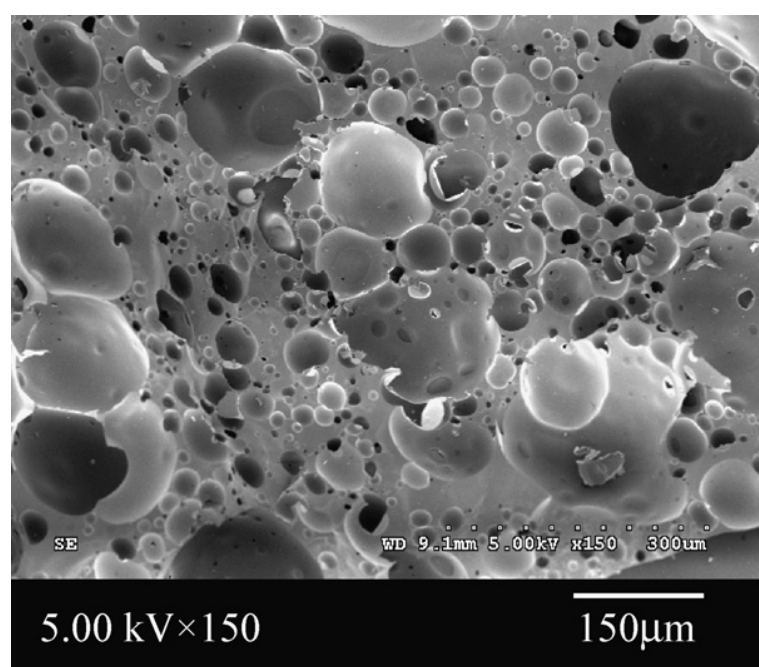

Fig. 8. SEM micrograph of the foam glass prepared from funnel glass by pyrovacuum reduction with the temperature, pressure, reducing agent and reaction time fixed at $700^{\circ} \mathrm{C}, 10 \mathrm{~Pa}, 5 \%$ and $0.5 \mathrm{~h}$, respectively.

Table 2

Chemical composition of the recovered metallic lead by ICP-OES

\begin{tabular}{ll}
\hline Element & wt\% \\
\hline $\mathrm{Pb}$ & 99.32 \\
$\mathrm{Na}$ & 0.26 \\
$\mathrm{Si}$ & 0.17 \\
$\mathrm{~K}$ & 0.07 \\
$\mathrm{Al}$ & 0.01 \\
$\mathrm{Fe}$ & 0.01 \\
$\mathrm{Ca}$ & 0.03 \\
$\mathrm{Mg}$ & 0.01 \\
\hline
\end{tabular}

\subsection{Properties of the recovered lead}

Metallic lead, which was evaporated from the funnel glass and condensed on the inner wall of the quartz tube, was recovered and examined by XRD and ICP-OES.

Fig. 7 illustrates that no other crystal phase except metallic lead could be observed in the XRD spectrum of the recovered metal. To further understand the chemical composition of the recovered metal, the product was digested and analyzed by ICP-OES and the results are shown in Table 2. It can be seen that lead occupied 99.3\% in the recovered product. The other elements, occupied less than $0.7 \%$, were mainly $\mathrm{Na}(0.26 \%), \mathrm{Si}(0.17 \%)$ and $\mathrm{K}(0.07 \%)$, respectively.

Table 3

TCLP analytical results for the residues after the pyrovacuum process

\begin{tabular}{|c|c|c|c|c|c|}
\hline Temperature $\left({ }^{\circ} \mathrm{C}\right)$ & Pressure (Pa) & Carbon adding amount (\%) & Holding time (h) & Recovery rate (\%) & $\mathrm{Pb}(\mathrm{mg} / \mathrm{L})$ \\
\hline 600 & 10 & 9 & 4 & 21.94 & 262.71 \\
\hline 700 & 10 & 9 & 4 & 45.52 & 159.37 \\
\hline 800 & 10 & 9 & 4 & 89.05 & 113.64 \\
\hline 900 & 10 & 9 & 4 & 93.53 & 5.91 \\
\hline 1000 & 10 & 9 & 4 & 97.47 & 1.29 \\
\hline 1000 & 100 & 9 & 4 & 97.80 & 1.06 \\
\hline 1000 & 1000 & 9 & 4 & 96.42 & 2.21 \\
\hline 1000 & 10000 & 9 & 4 & 25.08 & 210.64 \\
\hline 1000 & 1000 & 0 & 4 & 88.05 & 118.88 \\
\hline 1000 & 1000 & 2 & 4 & 95.62 & 14.56 \\
\hline 1000 & 1000 & 5 & 4 & 97.72 & 0.91 \\
\hline 1000 & 1000 & 9 & 4 & 98.59 & 0.43 \\
\hline 1000 & 1000 & 5 & 0.5 & 75.47 & 85.83 \\
\hline 1000 & 1000 & 5 & 1 & 88.60 & 68.68 \\
\hline 1000 & 1000 & 5 & 2 & 94.52 & 24.64 \\
\hline 1000 & 1000 & 5 & 6 & 98.07 & 1.55 \\
\hline
\end{tabular}




\subsection{Properties of the foam residues}

Some of the residues after the treatment were in porous form. To our best knowledge, this is the first to use pyrovacuum process for foam glass preparation, and furthermore, these foams are harmless because lead-contained in the funnel glass could be completely separated and recovered. One example is shown in Fig. 8.

All the parameters discussed in this paper may have reverse impact on lead recovery rate and the characteristics of foam glass. For example, lead recovery rate increased with increasing carbon amount and time, and these parameters led to an extension of pores "coalescence" [24], which might weak its physical properties. Thus, it is important to adjust these parameters to obtain a sufficient lead recovery rate and a foam glass with high quality. Details will be studied in our future work.

Table 3 presents the lead concentrations of the TCLP leachates for all residues after the treatment by the pyrovacuum reduction. Generally, the lowest lead concentrations were obtained when the temperature, reducing agent, reaction time were at their maximum values and the pressure was at its lower value, i.e., lead concentration was $1.29 \mathrm{mg} / \mathrm{L}$ with the temperature, reducing agent, reaction time and pressure fixed at $1000{ }^{\circ} \mathrm{C}, 9 \%, 4 \mathrm{~h}$ and $10 \mathrm{~Pa}$, respectively. Second, lower concentrations of lead were obtained from the residues with a higher lead recovery rate, and vice versa. It may be concluded that lead concentration is inversely proportional to its lead recovery rate. Third, the concentrations that exceed the regulatory limit of $5.0 \mathrm{mg} / \mathrm{L}$ for TCLP lead $[25,26]$ all have a lead recovery rate lower than $96 \%$, as seen in Table 3 . Thus, for safe treatment of funnel glass, it is necessary to obtain a relative higher lead recovery rate, such as higher than $96 \%$, to meet the TCLP lead threshold.

\section{Conclusions}

The dramatic effect of pyrovacuum reduction on the detoxification and reutilization of lead-contained funnel glass was well demonstrated in this study. Lead, with a purity of $99.3 \%$, was successfully separated and recovered from the funnel glass in the process, which attributed to the vitreous lead oxides changing to metallic lead by carbon and the lower boiling point of metallic lead at vacuum condition. The maximum lead removal rate reached 98.6\% when the temperature, pressure, carbon adding amount and holding time were $1000^{\circ} \mathrm{C}, 1000 \mathrm{~Pa}, 9 \%$ and $4 \mathrm{~h}$, respectively. Meanwhile, foam glass was synchronously developed in the pyrovacuum process. TCLP test indicated that lead leached from the foam glass was below the regulated value at optimum conditions. Therefore, it is believed that the pyrovacuum process developed in this study is an applicable option for CRT funnel glass detoxification and reutilization.

\section{Acknowledgements}

This work was financially supported, in part, by the National Basic Research Program of China with a funding number of
2007CB407303 and National Natural Science Foundation of China with a funding number of 50708110 .

\section{References}

[1] F. Andreola, L. Barbieri, A. Corradi, I. Lancellotti, CRT glass state of the art - a case study: recycling in ceramic glazes, J. Eur. Ceram. Soc. 27 (2007) 1623-1629.

[2] C. Hicks, R. Dietmar, M. Eugster, The recycling and disposal of electrical and electronic waste in China-legislative and market responses, Environ. Impact. Assess. Rev. 25 (2005) 459-471.

[3] The Basel Action Network (BAN), The Silicon Valley Coalition (SVTC), Toxics Link India, SCOPE (Pakistan), Greanpeace China, 2002. Exporting Harm: the high-tech trashing of Asia, http://www.svtc.org/cleance/pubs/technotrash.pdf.

[4] M.H. Wong, S.C. Wu, W.J. Deng, X.Z. Yu, Q. Luo, A.O.W. Leung, C.S.C. Wong, W.J. Luksemburg, A.S. Wong, Export of toxic chemicals - a review of the case of uncontrolled electronic-waste recycling, Environ. Pollut. 149 (2007) 131-140.

[5] W. He, G. Li, X. Ma, H. Wang, J. Huang, M. Xu, C. Huang, WEEE recovery strategies and the WEEE treatment status in China, J. Hazard. Mater. 136 (2006) 502-512.

[6] X.B. Liu, M. Tanaka, Y. Matsui, Electrical and electronic waste management in China: progress and the barriers to overcome, Waste Manage. Res. 24 (2006) 92-101.

[7] F. Méar, P. Yot, M. Cambon, M. Ribes, The characterization of waste cathode-ray tube glass, Waste Manage. 26 (2006) 1468-1476.

[8] F. Méar, P. Yot, M. Cambon, A.M. Ribes, Elaboration and characterisation of foam glass from cathode ray tubes, Adv. Appl. Ceram. 104 (2005) 123-130.

[9] E. Bernardo, F. Albertini, Glass foams from dismantled cathode ray tubes, Ceram. Int. 32 (2006) 603-608.

[10] E. Bernardo, G. Scarinci, S. Hreglich, G. Zangiacomi, Effect of time and furnace atmosphere on the sintering of glasses from dismantled cathode ray tubes, J. Eur. Ceram. Soc. 27 (2007) 1637-1643.

[11] E. Bernardo, G. Scarinci, S. Hreglich, Foam glass as a way of recycling glasses from cathode ray tubes, Glass Sci. Technol. 78 (2005) 7-11.

[12] F. Méar, P. Yot, R. Viennois, M. Ribes, Mechanical behaviour and thermal and electrical properties of foam glass, Ceram. Int. 33 (2007) 543-550.

[13] E. Bernardo, G. Scarinci, Sintering behaviour and mechanical properties of $\mathrm{Al}_{2} \mathrm{O}_{3}$ platelet-reinforced glass matrix composites obtained by powder technology, Ceram. Int. 30 (2004) 785-791.

[14] E. Bernardo, G. Scarinci, S. Hreglich, Mechanical properties of metal-particulate lead-silicate glass matrix composites obtained by means of powder technology, J. Eur. Ceram. Soc. 23 (2003) 1819-1827.

[15] E. Bernardo, R. Castellan, S. Hreglich, I. Lancellotti, Sintered sanidine glassceramics from industrial wastes, J. Eur. Ceram. Soc. 26 (2006) 3335-3341.

[16] E. Bernardo, R. Castellan, S. Hreglich, Sintered glass-ceramics from mixtures of wastes, Ceram. Int. 33 (2007) 27-33.

[17] F. Andreola, L. Barbieri, A. Corradi, I. Lancellotti, Cathode ray tube glass recycling: an example of clean technology, Waste Manage. Res. 23 (2005) 314-321.

[18] F. Méar, P. Yot, M. Cambon, M. Ribes, The changes in lead silicate glasses induced by the addition of a reducing agent (TiN or SiC), J. Non-Cryst. Solids 351 (2005) 3314-3319.

[19] F. Méar, P. Yot, M. Ribes, Effects of temperature, reaction time and reducing agent content on the synthesis of macroporous foam glasses from waste funnel glasses, Mater. Lett. 60 (2006) 929-934.

[20] Industry Council for Electronic Equipment Recycling (ICER), 2003. New Approach to Cathode Ray Tube (CRT) Recycling, http://www.icer.org.uk/ IcerDtiCrtFinal.pdf.

[21] C.H. Lee, C.S. Hsi, Recycling of scrap cathode ray tubes, Environ. Sci. Technol. 36 (2002) 69-75.

[22] S. Yamasaki, Digestion method for total element analysis, in: Method of Soil Environmental Analysis, Japanese society of soil science and plant Nutrition, Hakuyusya, Tokyo 1997, pp. 278-288, (in Japanese).

[23] Y.J. Liang, Y.C. Che, Inorganics Thermodynamics Manual, Northeastern University Press, Shenyang, 1994 (in Chinese).

[24] Y.N. Dai, B. Yang, Vacuum Metallurgy of Nonferrous Metallic Materials, Metallurgical Industry Press, Beijing, 2006 (in Chinese).

[25] Y.C. Jang, T.G. Townsend, Leaching of lead from computer printed wire boards and cathode ray tubes by municipal solid waste landfill leachates, Environ. Sci. Technol. 37 (2003) 4778-4784.

[26] S.E. Musson, Y.C. Jang, T.G. Townsend, I.H. Chung, Characterization of lead leachability from cathode ray tubes using the toxicity characteristic leaching procedure, Environ. Sci. Technol. 34 (2000) 4376-4381. 